\title{
Toward the Development of a Field Methodology for Evaluating Discomfort Glare From Automobile Headlamps
}

\author{
Michael Sivak and Paul L. Olson
}

\begin{abstract}
The aim of this research was to collect information and experimental data toward the development of a universally acceptable methodology for evaluating discomfort glare from vehicle headlamps. Three separate studies were performed: (a) an international survey of experts in headlighting and vision, soliciting opinions on desirable aspects of such a methodology; (b) a field evaluation of a proposed methodology at a speed of $50 \mathrm{~km} / \mathrm{hr}(30 \mathrm{mph})$; and (c) a field evaluation at $100 \mathrm{~km} / \mathrm{hr}(60 \mathrm{mph})$. The findings of this research suggest that the proposed methodology, which is easy to set up and implement, provides relatively reliable and valid measures of discomfort glare, and is time-efficient with respect to data collection.
\end{abstract}

The aim of this research was to collect information and experimental data toward the development of a methodology to evaluate discomfort glare from vehicle headlamps. The intended product of this research is a methodology that is valid, reliable, easy to set up and implement, timeefficient in respect to data collection, and universally applicable. Such a methodology

Drs. Michael Sivak and Paul L. Olson are research scientists at the University of Michigan Transportation Research Institute, 2901 Baxter Road, Ann Arbor, MI 48109-2150.

This study was supported by the Motor Vehicle Manufacturers Association (MVMA). is required for making progress toward potential harmonization of the differences between European and U.S. headlamp beam patterns (Olson, 1977).

This research consisted of the following three studies:

1. An international survey of experts in headlighting and vision, soliciting opinions on desirable aspects of such a methodology;

2. Field testing of a proposed discomfortglare evaluation methodology at intermediate speeds $(50 \mathrm{~km} / \mathrm{hr}$ [30 $\mathrm{mph}]) ;$ and

3 . Field testing of a proposed discomfortglare evaluation methodology at high speeds $(100 \mathrm{~km} / \mathrm{hr}[60 \mathrm{mph}])$. 


\section{Respondents}

A written questionnaire was sent to 43 experts in headlighting and vision. The contacted persons represented academia, industry, and government. A total of 28 persons returned a completed questionnaire, a response rate of about $65 \%$. Table 1 presents a tabulation by country of contacted and responding experts.

\section{Questionnaire and Results}

The questionnaire consisted of eight questions. Each question was presented in a four-alternative forced-choice format. The actual questions and the distributions of the responses are shown in Table 2.

TABLE 1

DISTRIBUTION OF CONTACTED AND RESPONDING EXPERTS BY COUNTRY

\begin{tabular}{lcc}
\hline \multicolumn{1}{c}{ Country } & $\begin{array}{c}\text { Muber } \\
\text { Contacted }\end{array}$ & $\begin{array}{c}\text { Munber } \\
\text { Responding }\end{array}$ \\
\hline United States & 10 & 10 \\
Australia & 4 & 4 \\
West Ge rmany & 5 & 3 \\
Sweden & 4 & 3 \\
Canada & 5 & 2 \\
The Netherlands & 5 & 2 \\
Japan & 2 & 2 \\
United Kingdom & 4 & 1 \\
France & 1 & 1 \\
Finiand & 1 & 0 \\
Spain & 1 & 0 \\
Switzerland & 1 & 0 \\
\hline
\end{tabular}

\section{Discussion}

The analysis in Table 2 suggests that discomfort-glare evaluation on a straight roadway was the primary issue of concern, with $42 \%$ of the respondents rating this aspect as an essential component of a desirable methodology. Straight roadway was followed (in decreasing order of essential responses) by vertical misaim, field aspect, hills, and driver as the rater. These aspects were rated by at least one third of the respondents as being essential. On the other hand, the least important issues (again in decreasing order of importance) were sags, rapid evaluation, rater experience, rater sex, and rater education. These aspects were rated as being essential by fewer than $10 \%$ of the respondents. The preferred response scale was a 9 -point scale; $43 \%$ of respondents selected this scale.

Based partly on the results of the survey of experts in Study 1, a methodology was developed for evaluating discomfort glare. This methodology was then tested under intermediate speeds (Study 2) and high speeds (Study 3).

STUDY 2: TESTING THE METHODOLOGY AT INTERMEDIATE SPEEDS

\section{Experimental Design}

Proposed methodology for evaluating discomfort glare. The following methodolngy for evaluating discomfort glare was tested:

1. The observer vehicle is driven at 50 $\mathrm{km} / \mathrm{hr}(30 \mathrm{mph})$ on a straight, level roadway towards a stationary glare vehicle in the adjacent lane.

2. The lamps of the glare vehicle are on for the vehicle separation of 400 to $300 \mathrm{~m}$ $(1,312$ to $984 \mathrm{ft})$, and then again for the vehicle separation of 150 to $50 \mathrm{~m}(492$ to $164 \mathrm{ft})$.

3. Glare is rated on the de Boer scale (de Boer, 1973). This is a 9-point scale with qualifiers only for the odd points as follows: 1 (unbearable), 2, 3(disturbing), 4, 5 (just acceptable), 6,7 (satisfactory), 8,9 (just noticeable).

4. Two ratings are obtained for each 


\begin{tabular}{|c|c|c|c|c|}
\hline \multirow[b]{2}{*}{ Question } & \multicolumn{4}{|c|}{ x Responses } \\
\hline & $\begin{array}{l}\text { Not } \\
\text { Important }\end{array}$ & Important & $\begin{array}{l}\text { Very } \\
\text { Important }\end{array}$ & Essential \\
\hline \multicolumn{5}{|l|}{ How important is discomfort-glare evaluation in estab- } \\
\hline $\begin{array}{l}\text { How important is field as opposed to laboratory evalu- } \\
\text { ation of discomfort glare? }\end{array}$ & 0 & 18 & 46 & 36 \\
\hline $\begin{array}{l}\text { How important is dymamic (all participants moving) as } \\
\text { opposed to static evaluation of discomfort glare? }\end{array}$ & \multicolumn{3}{|c|}{ How important is dynamic (all participants moving) as } & 29 \\
\hline $\begin{array}{l}\text { In a dynamic evaluation, how important is it for the } \\
\text { rater to be a driver as opposed to a passenger? }\end{array}$ & 11 & 30 & 26 & 33 \\
\hline \multicolumn{5}{|l|}{$\begin{array}{l}\text { How important is it to include the following situations } \\
\text { in discomfort glare evaluation: }\end{array}$} \\
\hline Straight roadway & 4 & 23 & 31 & 42 \\
\hline Left curves & 12 & 23 & 35 & 31 \\
\hline Right curves & 19 & 23 & 42 & 15 \\
\hline $\mathrm{Hills}$ & 15 & 23 & 27 & 35 \\
\hline Sags & 44 & 36 & 12 & 8 \\
\hline Horizontal misaim & 19 & 46 & 19 & 15 \\
\hline Vertical misaim & 8 & 19 & 35 & 38 \\
\hline \multicolumn{5}{|l|}{$\begin{array}{l}\text { How important is it to consider the following observer } \\
\text { variables: }\end{array}$} \\
\hline Age & 0 & 25 & 46 & 29 \\
\hline Sex & 59 & 37 & 4 & 0 \\
\hline Education & 74 & 22 & 4 & 0 \\
\hline Experience & 30 & 48 & 19 & 4 \\
\hline \multirow[t]{2}{*}{$\begin{array}{l}\text { How important is it for the discomfort-glare evaluation } \\
\text { to be relatively rapid? }\end{array}$} & 22 & 43 & 30 & 4 \\
\hline & 9-point & 3-point & 2-point & $\begin{array}{l}\text { other or no } \\
\text { preference }\end{array}$ \\
\hline $\begin{array}{l}\text { What is the preferred rating scale for discomfort-glare } \\
\text { evaluation? }\end{array}$ & 43 & 18 & 4 & 36 \\
\hline
\end{tabular}

Note. The number of responses per question varied from 23 to 28 .

run, one for the vehicle separation of 400 to $300 \mathrm{~m}(1,312$ to $984 \mathrm{ft})$, and the other one for the vehicle separation of 150 to $50 \mathrm{~m}$ (492 to $164 \mathrm{ft}$ ). Subjects memorize the first rating, and record both ratings after the second exposure.
Test site. The test was performed on a flat and straight private road with no significant illumination. Each lane of this two-lane, asphalt roadway was about $3 \mathrm{~m}$ ( $10 \mathrm{ft}$ ) wide.

Test vehicles. The subjects were driving 
(and riding) in a 1983 General Motors fullsize station wagon. The stationary glare car was a 1981 full-size Ford station wagon.

Rater position in the car. To investigate the potential effects of rater position in the car (and of driving load), cach subject served as a driver, center-front passenger, and rightfront passenger.

Illumination levels. On each trial, subjects were shown one of the following four glare stimuli: (a) standard U.S. high beams, (b) standard U.S. high beams filtered with neutral density filters having transmissivity of $18 \%$, (c) standard U.S. low beams, and (d) standard U.S. low beams filtered with neutral density filters having transmissivity of $18 \%$.

These four glare stimuli produced (at two vehicle separations) eight illumination levels ranging from 0.035 to 5.1 lux. These measurements were taken at the end of the glare exposure (i.e., at vehicle separations of 300 $\mathrm{m}[984 \mathrm{ft}]$ and $50 \mathrm{~m}$ [164 ft] inside of the subject's car at the approximate location of the eyes of the center-front passenger. The measurements evaluated the sum of the illumination from the glare car and the ambient illumination. The headlamps of the subject's car were off during these measurements. (Because of the scattering of the light by the filters, the lux values for the filtered low beams are substantially above what would be predicted based only on the transmissivity of the filters.)

The particular illumination levels were selected because it was hoped that they will lead to responses covering the whole range of the response scale. (All eight illumination levels were produced from the same physical units - a total of two large rectangular sealed beams [No. 6052]. Consequently, subjects could not identify which stimulus was being shown based on the location, number, or size of the illuminated headlamps.)

Adaptation illumination. The adaptation illumination was measured inside of the subject's car (with the headlamps of the subject's car on and the headlamps of the glare car off) at the approximate position of the eyes of the center-front passenger. This illumination was approximately $0.055 \mathrm{lux}$.

Subjects. A total of 12 volunteers participated as subjects. To investigate the effects of age on discomfort-glare rating, the subject group consisted of both older and younger persons. Six subjects (three males and three females) were between 67 and 73 years of age, and six (four males and two females) were between 19 and 23 years of age.

Procedure. Three subjects were tested at a time. Each subject had a clipboard with a response sheet that had the response (de Boer) scale printed on the top, and each had a miniature flashlight to be able to record the responses without major changes in the level of dark-adaptation. The driver was instructed to drive at about $50 \mathrm{~km} / \mathrm{hr}(30$ $\mathrm{mph}$ ). All subjects were asked to look straight ahead, but not directly into the headlights of the glare car.

Two experimenters ran the study. One was seated in the back seat of the subjects' car. His task was to signal, via a handheld radio, when the subjects' car passed four cones at four vehicle-separation landmarks (i.e., $400,300,150$, and $50 \mathrm{~m}[1,312,984$, 492 , and $164 \mathrm{ft}]$. Specifically, he indicated "on" at $400 \mathrm{~m}(1,312 \mathrm{ft})$, "off" at $300 \mathrm{~m}$ (984 $\mathrm{ft}$ ), "on" at $150 \mathrm{~m}(492 \mathrm{ft})$, and "off" at $50 \mathrm{~m}$ $(164 \mathrm{ft})$. The second experimenter, seated in the stationary glare car, turned the glare car's headlights on at $400 \mathrm{~m}(1,312 \mathrm{ft})$, off at $300 \mathrm{~m}(984 \mathrm{ft})$, on at $150 \mathrm{~m}(492 \mathrm{ft})$, and off at $50 \mathrm{~m}(164 \mathrm{ft})$. Additionally, this experimenter selected, for each trial, the beam to be shown and inserted/removed the filters.

Two replications of each stimulus were shown to each subject at each seating position and at each vehicle separation. (This allowed a more precise estimation of the discomfort and allowed for a test of the reliability of the responses.) This design resulted in 48 trials per subject ( 2 vehicle separations $\times 2$ beams $\times 2$ filters $\times 3$ positions in the car $\times 2$ replications). Each experimental session, including four practice trials and two short breaks for rotation of subjects' positions, lasted about 90 minutes. 


\section{Results}

Analysis of variance. The results of the analysis of variance on discomfort-glare ratings (with illumination level, age, rater position, and replication as factors) were as follows:

Illumination level. The effect of illumination level (Table 3, column "All Subjects" - with entries in the decreasing order of the ratings) was statistically significant $(F[7,70]=143.17, p<.01)$.

Age. The effect of age was statistically significant, with older subjects reporting less discomfort ( $M$ [mean glare rating] $=6.0)$ than younger subjects $(M=5.3)(F[1,10]=$ $4.91, p=0.05$ ).

Rater position. The differences among the ratings of drivers $(M=5.6)$, center-front passengers $(M=5.5)$, and right-front passengers $(M=5.8)$ were not statistically significant $(F[2,20]=1.24, p>.05)$.

Replications. The difference between the ratings for the first replications of each stim- ulus $(M=5.7)$ and the second replications $(M=5.6)$ was not statistically significant $(F[1,10]=1.65, p>.05)$.

Interactions. From among all interactions, only two reached statistical significance: illumination level $\times$ age (Table 3 , columns "Older Subjects" and "Younger Subjects") $(F[7,70]=4.64, p<.05)$ and replications $\times$ age $(F[1,10]=8.56, p<.05)$, with older subjects tending to report more glare for first replications and younger subjects for second replications.

Relation of glare ratings to illumination. Glare responses were significantly related to the illumination reaching the eyes of the observers, whether measured in lux $(r[574]=$ $-.64, p<.01)$ or the logarithm of illumination $(r[574]=-.71, p<.01)$.

Glare angle/vehicle separation. The confounded effect of glare angle/vehicle separation, when controlling for the effect of the logarithm of the illumination reaching the

\begin{tabular}{|c|c|c|c|c|c|c|}
\hline \multirow[b]{2}{*}{$\begin{array}{l}\text { I1 wination } \\
\text { (1ux) }\end{array}$} & \multirow[b]{2}{*}{$\begin{array}{l}\text { Vehicle } \\
\text { Separation }\end{array}$} & \multirow[b]{2}{*}{ Bean } & \multirow[b]{2}{*}{ Fillter } & \multicolumn{3}{|c|}{ Mean Rating } \\
\hline & & & & $\begin{array}{c}\text { Al1 } \\
\text { Subjects }\end{array}$ & $\begin{array}{l}\text { 01der } \\
\text { Subjects }\end{array}$ & $\begin{array}{l}\text { Younger } \\
\text { Subjects }\end{array}$ \\
\hline 0.035 & $400-300 \mathrm{~m}^{\mathrm{a}}$ & low & yes & 8.0 & 7.9 & 8.2 \\
\hline 0.190 & $150-50 \mathrm{~m}^{\mathrm{b}}$ & $10 \mathrm{w}$ & yes & 7.8 & 7.6 & 7.9 \\
\hline 0.070 & $400-300 \mathrm{~m}$ & hi gh & yes & 6.6 & 7.3 & 5.8 \\
\hline 0.070 & $400-300 \mathrm{~m}$ & low & no & 6.6 & 7.2 & 5.9 \\
\hline 0.370 & $150-50 \mathrm{~m}$ & low & no & 6.4 & 6.8 & 5.9 \\
\hline 0.700 & $150-50 \mathrm{~m}$ & high & yes & 4.7 & 5.5 & 3.9 \\
\hline 0.350 & $400-300 \mathrm{~m}$ & high & no & 3.2 & 3.8 & 2.7 \\
\hline 5.100 & $150-50 \mathrm{~m}$ & high & no & 1.7 & 1.8 & 1.6 \\
\hline
\end{tabular}

${ }_{1,312-984} \mathrm{ft} . \mathrm{b}_{492-164 \mathrm{ft} .}$ 
eyes of the observer, was statistically significant. The ratings for the $0.6^{\circ}$ glare angle $(M=4.1)$ were more discomforting than for the $3.8^{\circ}$ glare angle $(M=7.1)(F[1,573]=$ $355.9, p<.01)$. The glare angle of $0.6^{\circ}$ was always associated with the vehicle separation of 400 to $300 \mathrm{~m}(1,312$ to $984 \mathrm{ft})$, and the glare angle of $3.8^{\circ}$ was always associated with the vehicle separation of 150 to $50 \mathrm{~m}$ (492 to $164 \mathrm{ft}$ ). (The glare angles were computed for the center-front passenger at 300 $\mathrm{m}[984 \mathrm{ft}]$ and $50 \mathrm{~m}[164 \mathrm{ft}]$.)

Variance accounted. The results of stepwise regression analyses indicate that $51 \%$ of the variance of the glare ratings can be accounted for by the logarithm of illumination, $70 \%$ by the logarithm of illumination and age, and $72 \%$ by the logarithm of illumination, age, and glare angle/vehicle separation.

\section{Discussion}

The principal results of this study, applicable to the tested speed of $50 \mathrm{~km} / \mathrm{hr}$ (30 $\mathrm{mph}$ ), are as follows:

1. The proposed methodology provided relatively reliable measures, as there was no main effect of replications. However, interaction of replications $\times$ age was statistically significant. Specifically, there was a tendency for younger respondents to assign more discomforting responses to the second presentation of the stimulus. (This tendency was reversed for older subjects.)

2. Position in the car (and thereby also driving vs. nondriving) had no effect on glare ratings. This is an important finding, indicating that glare ratings could be obtained from up to three raters at a time, without a reduction in validity of the ratings.

3. There was, as expected, a main effect of age. However, this effect was in the 11nexpected direction: Older subjects reported less discomfort glare than did younger subjects (cf. Wolf, 1960). There are two possible post hoc explanations of the present finding. The first explanation is based on subject sampling. Specifically, although the sample of younger drivers might have been typical of their age group, the sample of older sub- jects was quite likely not representative. Since the study relied on volunteers who were willing to drive late at night on an unknown road, it is likely that the sample of older subjects was skewed towards more physically fit persons. The second possible explanation is based on the finding that older persons are more likely to respond to survey questions in a manner that they believe meets with the approval of others (Campbell, Converse, \& Rogers, 1976). According to this hypothesis, older subjects would be more likely to report low levels of discomfort glare, because they may believe that those are the answers desired. This hypothesis is strengthened by the finding of a significant illumination $\times$ age interaction: Although for the six most discomforting stimuli older subjects did report less discomfort glare than did younger subjects, for the two least discomforting stimuli the effect was reversed. (For these latter stimuli the glare experiences are in the "desirable" [nondiscomforting] end of the response range. Consequently, adjustments of the responses toward the less discomforting end of the scale are not necessary for these stimuli.)

4. The methodology provided valid measures because (a) the measures were found to correlate significantly with the illumination reaching the eyes of the observers; and (b) when controlling for the effects of illumination reaching the eyes of the observer, the conditions with the smaller glare angle produced more discomforting responses.

STUDY 3: TESTING THE METHODOLOGY AT HIGH SPEEDS

\section{Experimental Design}

The experimental design was identical to the design in Study 2, except for the following:

Test site. A proving-grounds straightaway was the test site for this study. Each lane of this two-lane, asphalt roadway is about $3 \mathrm{~m}$ $(10 \mathrm{ft})$ wide.

Test vehicles. The subjects were riding in a 
1987 General Motors full-size station wagon. The stationary glare car was identical to the one used in Study 2.

Rater position in the car. Only the centerfront and right-front passengers were raters in this study. (Because of the high speed in this study, the driver was a professional driver who provided no glare ratings.) The subjects remained in their original positions during the entire experimental session.

Illumination levels. The same combinations of beams, filters, and vehicle separations were used as in Study 2, resulting in approximately the same illumination levels as in Table 3. (Because the glare car, the body style of the subjects' car, and the width of the test road were the same as in Study 2, no separate photometry was performed in this study.)

Adaptation illumination. The adaptation illumination was comparable to the illumination in Study 2. (As indicated above, no separate photometry was performed in this study.)

Subjects. A total of eight volunteers participated as subjects: Four subjects (three males and one female) were between 64 and 73 years of age, and four (two males and two females) were between 20 and 21 years of age. (Four of the eight subjects also participated in Study 2.)

Procedure. Two subjects were tested at a time, one in the center-front position and one in the right-front position. The driver was instructed to drive at about $100 \mathrm{~km} / \mathrm{hr}$ (60 mph).

The same vehicle separations were used as in Study 2 (i.e., 400 to $300 \mathrm{~m} \mathrm{[1,312}$ to 984 $\mathrm{ft}$ ], and 150 to $50 \mathrm{~m} \mathrm{[492} \mathrm{to} 164 \mathrm{ft}$ ]. Since the speed was about twice the speed in Study 2 , the time duration of exposure to glare was about one half of the time duration in Study 2.

Three replications of each stimulus were shown to each subject at each vehicle sepa- ration. This design resulted in 24 trials per subject $(2$ vehicle separations $\times 2$ beams $\times 2$ filters $\times 3$ replications). Each experimental session, including four practice trials, lasted about 45 minutes.

\section{Results}

Analysis of variance. The results of the analysis of variance on discomfort-glare ratings (with illumination level, age, rater position, and replication as factors) were as follows:

Illumination level. The effect of illumination level (Table 4, column "All Subjects") was statistically significant $(F[7,28]=42.75$, $p<.01)$.

Age. The effect of age was statistically significant, with older subjects reporting less discomfort $(M=6.6)$ than younger subjects $(M=5.5)(F[1,4]=8.08, p<.05)$.

Rater position. The mean ratings of center-front passengers and right-front passengers were identical $(M=6.0)(F<1)$.

Replications. The mean ratings for each of the three replications were identical ( $M=$ 6.0) $(F<1)$.

Interactions. From among all interactions, only two reached statistical significance: illumination level $\times$ age (Table 4, columns "Older Subjects" and "Younger Subjects") $(F[7,28]=2.69, p<.05)$ and replications $\times$ age $(F[2,8]=7.60, p<.05)$, with older subjects tending to report most glare for first replications and younger subjects tending to report least glare for first replications.

Relation of glare ratings to illumination. Glare responses were significantly related to the illumination reaching the eyes of the observers, whether measured in lux $(r[190]=$ $-.61, p<.01)$ or the logarithm of illumination $(r[190]=-.68, p<.01)$.

Glare angle/vehicle separation. The confounded effect of glare angle/vehicle separation, when controlling for the effect of the logarithm of the illumination reaching the eyes of the observer, was statistically significant. The ratings for the $0.6^{\circ}$ glare angle $(M=4.7)$ were more discomforting than for the $3.8^{\circ}$ glare angle $(M=7.3)(F[1,189]=$ 


\begin{tabular}{|c|c|c|c|c|c|c|}
\hline \multirow[b]{2}{*}{$\begin{array}{l}\text { I1] wination } \\
\text { (1ux) }\end{array}$} & \multirow[b]{2}{*}{$\begin{array}{l}\text { Vehicle } \\
\text { Separation }\end{array}$} & \multirow[b]{2}{*}{ Bean } & \multirow[b]{2}{*}{ Filter } & \multicolumn{3}{|c|}{ Mean Rating } \\
\hline & & & & $\begin{array}{c}\text { A11 } \\
\text { Subjects }\end{array}$ & $\begin{array}{l}\text { 0lder } \\
\text { Subjects }\end{array}$ & $\begin{array}{l}\text { Younger } \\
\text { Subjects }\end{array}$ \\
\hline 0.035 & $400-300 \mathrm{~m}^{\mathrm{a}}$ & low & yes & 8.2 & 8.2 & 8.2 \\
\hline 0.190 & $150-50 \mathrm{~m}^{\mathrm{h}}$ & low & yes & 7.9 & 7.7 & 8.1 \\
\hline 0.070 & $400-300 \mathrm{~m}$ & high & yes & 7.0 & 7.5 & 6.4 \\
\hline 0.070 & $400-300 \mathrm{~m}$ & low & no & 6.8 & 7.4 & 6.2 \\
\hline 0.370 & $150-50 \mathrm{~m}$ & low & no & 6.4 & 6.9 & 5.9 \\
\hline 0.700 & $150-50 \mathrm{~m}$ & high & yes & 5.5 & 6.8 & 4.2 \\
\hline 0.350 & $400-300 \mathrm{~m}$ & high & no & 3.8 & 4.9 & 2.8 \\
\hline 5.100 & $150-50 \mathrm{~m}$ & high & no & 2.5 & 2.9 & 2.0 \\
\hline
\end{tabular}

${ }_{1,312-984 \mathrm{ft} .}{ }^{\mathrm{b}} 492-164 \mathrm{ft}$.

$6.34, p<.05$ ). (As in Study 2, the glare angle of $0.6^{\circ}$ was always associated with the vehicle separation of 400 to $300 \mathrm{~m}[1,312$ to $984 \mathrm{ft}$, and the glare angle of $3.8^{\circ}$ was always associated with the vehicle separation of 150 to $50 \mathrm{~m}$ [492 to $164 \mathrm{ft}$ ]).

Variance accounted. The results of stepwise regression analyses indicate that $47 \%$ of the variance of the glare ratings can be accounted for by the logarithm of illumination, $63 \%$ by the logarithm of illumination and age, and $68 \%$ by the logarithm of illumination, age, and glare angle/vehicle separation.

\section{Discussion}

The principal results of this study, applicable to the tested speed of $100 \mathrm{~km} / \mathrm{hr}$, are as follows:

1. The proposed methodology provided relatively reliable measures, as there was no main effect of replications. However, interaction of replications $\times$ age was statistically significant.
2. The effect of age was statistically significant: Older subjects reported less discomfort glare than did younger subjects. However, illumination level $\times$ age was statistically significant.

3. The methodology provided valid measures, because (a) the measures were found to correlate significantly with the illumination reaching the eyes of the observers; and (b) when controlling for the effects of illumination reaching the eyes of the observer, the conditions with the smaller glare angle produced more discomforting reponses.

\section{SUMMARY OF THE} EXPERIMENTAL FINDINGS

The experimental part of this research tested a proposed methodology for evaluating discomfort glare under intermediate and high speeds. The principal findings of this research are as follows:

1. The proposed methodology is easy to set up and implement.

2. The proposed methodology provides 
relatively reliable measures, as there was no main effect of replications in either of the two studies.

3. The proposed methodology provides valid measures of glare, because (a) the measures were found to correlate significantly with the illumination reaching the eyes of the observer and (b) the glare-angle effect (after controlling for the effect of illumination) was in the expected direction.

4. Discomfort-glare ratings were unaffected by the rater's position in the car. Consequently, the proposed methodology is time-efficient, since up to three raters can be used simultaneously.

5. Rater sampling appears to be an important consideration in using the proposed methodology, because the age effect was in the unexpected direction under both speed conditions.

6. The proposed methodology is relatively robust: Although there was a tendency for the intermediate-speed ratings to be more discomforting $(M=5.6)$ than the highspeed ratings $(M=6.0)$, this difference did not reach statistical significance when controlling for the effect of age $(F[1,17]=2.29$, $p>.1$ ).

\section{CONCLUSIONS}

The impetus for this research was the need for a universally acceptable methodology for evaluating discomfort glare from vehicle headlamps. The results are very encouraging: The proposed methodology, which is easy to set up and implement, provides relatively reliable and valid measures of discomfort glare and is time-efficient with respect to data collection. However, before this methodology can be recommended for general use, the following studies need to be performed:

1. A validation of the present unexpected age effect.

2. An evaluation of the effect of the first glare exposure on the rating of the second glare exposure and vice versa (because in the proposed methodology subjects make two ratings during each vehicle approach).

3. Cross-cultural replications of the basic findings.

\section{REFERENCES}

Campbell, A., Converse, P. E., \& Rogers, W. L. (1976). The quality of American life: Perceptions, evaluations, and satisfactions. New York: Russel Sage.

de Boer, J. B. (1973). Quality criteria for the passing beam of motorcar headlights. Paper presented at the GTB (Groupe de Travail mixte de Bruxelles) meeting, Walldorf, West Germany.

Olson, P. L. (1977). The relative merits of different low-beam headlighting systems (Report No. UMHSRI-77-55). Ann Arbor: Highway Safety Research Institute, The University of Michigan.

Wolf, E. (1960). Glare and age. Archives of Ophthalmology, 64, 502-514. 